\title{
Landmark Studies in Radiation Oncology: Has the Pattern of Publication Changed?
}

\author{
Carsten Nieder ${ }^{1,2 *}$, Hans Geinitz ${ }^{3}$, Nicolaus H Andratschke ${ }^{4}$ and Anca L Grosu
}

${ }^{1}$ Department of Oncology and Palliative Medicine, Nordland Hospital, 8092 Bodø, Norway

${ }^{2}$ Institute of Clinical Medicine, Faculty of Health Sciences, University of Tromsø, 9038 Tromsø, Norway

${ }^{3}$ Department of Radiation Oncology, Klinikum rechts der Isar der Technischen Universität München, 81675 München, Germany

${ }^{4}$ Department of Radiation Oncology, University Hospital Rostock, 18059 Rostock, Germany

${ }^{5}$ Department of Radiation Oncology, University Hospital Freiburg, 79106 Freiburg, Germany

\begin{abstract}
The purpose of this study was to identify current pattern of publication of the most influential radiation oncology research, and to compare these to previous pattern. From several potential measures of impact and relevance of research, we selected article citation rate because landmark or practice-changing research is likely to be cited frequently. The citation database Scopus was used to identify the 100 most frequently cited articles published between 2009 and 2011, and 1999-2001, respectively. Current top 100 articles achieved a median of 57 citations (range 181-38). Top 100 articles from the time period 1999-2001 achieved a median of 208 citations (range 1149121). The number of authors per highly cited article has increased significantly. Recently, $58 \%$ of articles were written by more than 10 authors (1999-2001: only 25\%). Significantly fewer articles were published by authors from the US and/or Canada (53\% versus $73 \%$ ). Pure European contributions increased from $20 \%$ to $33 \%$. The proportion of publications related to breast, lung or lower gastrointestinal tract cancer increased, while that related to prostate or gynecological cancer decreased significantly. Irrespective of time period, pattern of publication was dominated by only two scientific journals: the Journal of Clinical Oncology and the International Journal of Radiation Oncology Biology and Physics. Several newly launched journals have managed to attract highly cited articles. Fifteen of the 20 journals $(75 \%)$ that featured top 100 articles from the time period 1999-2001 were no longer represented on the recent top 100 list. Inspite of changing pattern of publication, relatively few well established journals dominate.
\end{abstract}

Keywords: Radiation oncology; Radiotherapy; Research evaluation; Scientific publishing; Citation

\section{Introduction}

Dissemination of scientific results has never been easier and faster than in recent years. With the advent of web-based publication channels and search engines, the number of options has increased rapidly. In parallel, more and more peer-reviewed journals with focus on different aspects of cancer treatment have entered the arena. For several reasons including but not limited to tenure track or likelihood of future funding, researchers attempt to publish their results in a way that ensures high visibility and allows for broad adoption of the progress achieved. Landmark studies often appear in traditional and prestigious high impact journals. However, the impact factor of and criteria for acceptance of manuscripts in scientific journals might change over time. All of these developments might have resulted in changing pattern of publication. The purpose of this study was to identify current pattern of publication of the most influential radiation oncology research, and to compare these to previous pattern. Ideally, the definition and selection of influential research should not depend on subjective preferences. From several potential measures of impact and relevance of research, we selected article citation rate because landmark or practice-changing research is likely to be cited by successor trials, editorials, review articles, guidelines etc.

\section{Methods}

A systematic search of the citation database Scopus (Elsevier B.V., www.scopus.com) by use of the function 'document search' and the term search for 'radiotherapy OR radiation oncology' in all fields was performed on $30^{\text {th }}$ November 2012. Articles published during the time period 2009-2011 were selected irrespective of subject area, language, document and article type (review, clinical study, experimental study etc.). Then, these articles were ranked by number of citations (field 'times cited' in the Scopus citation database) in order to create a list (top 100) of articles with the highest number of citations. For these top 100 publications the following parameters were evaluated: journal in which an article was published, region of origin, number of authors, topic, and type of research. The same methods were applied to extract and analyze the top 100 publications of the time period 1999-2001. The Chi square test was used to compare pattern of publication. A complete list of top 100 articles is provided as a supplement at the end of this article.

\section{Results}

Between 2009 and 2011, 5772 articles related to different aspects of radiation oncology were published (1999-2001: only 2352 articles). Current top 100 articles achieved a median of 57 citations (range 18138). Top 100 articles from the period 1999-2001 achieved a median of 208 citations (range 1149-121). The references [1-20] represent the 10 most cited articles per time period. Table 1 show that the number of authors per highly cited article has increased significantly. Recently, $58 \%$ of articles were written by more than 10 authors (1999-2001: only

*Corresponding author: Carsten Nieder, MD, Department of Oncology and Palliative Medicine, Nordland Hospital, 8092 Bodø, Norway, Tel: +47 75578449 Fax: +47 7553 4975; E-mail: carsten.nieder@nlsh.no

Received February 05, 2013; Accepted February 28, 2013; Published March 03 2013

Citation: Nieder C, Geinitz H, Andratschke NH, Grosu AL (2013) Landmark Studies in Radiation Oncology: Has the Pattern of Publication Changed? J Cancer Sci Ther 5: 115-118. doi:10.4172/1948-5956.1000195

Copyright: ( 2013 Nieder C, et al. This is an open-access article distributed under the terms of the Creative Commons Attribution License, which permits unrestricted use, distribution, and reproduction in any medium, provided the original author and source are credited. 
25\%). Significantly fewer articles were published by authors from the US and/or Canada (53\% versus $73 \%$; statistics shown in Table 2). Pure European contributions increased from $20 \%$ to $33 \%$. The proportion of publications related to breast, lung or lower gastrointestinal tract cancer increased, while that related to prostate or gynecological cancer decreased significantly. No significant differences were found with regard to research or study type. The majority of articles reported on non-phase III clinical trials, and very few on radiobiology or physics research. Irrespective of time period, pattern of publication was dominated by only two scientific journals: the Journal of Clinical Oncology and the International Journal of Radiation Oncology Biology and Physics. However, the Journal of Clinical Oncology has strengthened its leading role (60\% versus $47 \%$ ). As presented in table 1 , several newly launched journals have managed to attract highly cited

\begin{tabular}{|c|c|c|}
\hline Parameter & 2009-2011 & $1999-2001$ \\
\hline \multicolumn{3}{|l|}{ No of authors } \\
\hline $1-3$ & 5 & 10 \\
\hline 4-6 & 13 & 23 \\
\hline $7-10$ & 24 & 42 \\
\hline$>10$ & 58 & 25 \\
\hline \multicolumn{3}{|l|}{ Geographic region } \\
\hline United States/Canada & 53 & 73 \\
\hline Europe & 33 & 20 \\
\hline Asia/Middle East & 6 & 2 \\
\hline Australia/New Zealand & 1 & 2 \\
\hline Multiple regions & 7 & 3 \\
\hline \multicolumn{3}{|l|}{ Type of publication } \\
\hline Meta-analysis & 3 & 2 \\
\hline Randomized phase III trial & 14 & 21 \\
\hline Other clinical trial & 59 & 60 \\
\hline Review & 11 & 8 \\
\hline Guideline/consensus paper & 10 & 5 \\
\hline Other incl. physics, radiobiology & 3 & 4 \\
\hline \multicolumn{3}{|l|}{ Topic of publication } \\
\hline Breast cancer & 24 & 10 \\
\hline Prostate cancer & 11 & 21 \\
\hline Brain tumor/metastases & 12 & 12 \\
\hline Head and neck cancer & 11 & 14 \\
\hline Lung cancer & 12 & 8 \\
\hline Lower gastrointestinal cancer & 9 & 3 \\
\hline Gynecological cancer & 3 & 8 \\
\hline \multicolumn{3}{|l|}{ Scientific journal } \\
\hline J Clin Oncol & 60 & 47 \\
\hline Int J Radiat Oncol Biol Phys & 15 & 29 \\
\hline JNCCN & 3 & 0 \\
\hline Radiother Oncol & 3 & 3 \\
\hline Lancet & 2 & 2 \\
\hline N Engl J Med & 0 & 2 \\
\hline Cancer Res & 0 & 2 \\
\hline Cancer & 0 & 2 \\
\hline Ann Oncol & 2 & 0 \\
\hline
\end{tabular}

Table 1: Comparison of top 100 radiation oncology publications.
Parameter and tested strata

Number of authors: 1-3, 4-6, 7-10, >10

Topic: Breast, Prostate, Lung, others

Region: USA/Canada, Europe, multiple, others

Journal: JCO, IJROBP, all others combined

Type of article: Phase III, other clinical, others p-value

$<0.0001$

0.017

0.032

0.049

$>0.2$
Table 2: Statistical comparisons (Chi square test). articles. Fifteen of the 20 journals (75\%) that featured top 100 articles from the time period 1999-2001 were no longer represented on the recent top 100 list.

\section{Discussion}

During the time period between 1999 and 2011, major progress has been achieved in the areas of multimodal treatment [21], implementation of highly conformal radiotherapy techniques [22,23], and imaging for treatment planning [24]. Several articles on these subjects were among those with the highest numbers of citations [13,6,14-17]. The objective of this review was to identify longitudinal changes in pattern of scientific publication of influential, highly cited radiation oncology research. After arbitrary decisions about which database to search (only those providing citation numbers could be considered for the purpose of our review) and which keywords to use, we performed a systematic literature search and applied a broad definition of radiation oncology related publication, including for example general reviews and guidelines on local treatment of breast or prostate cancer where radiotherapy is part of the armamentarium [20]. Citation rate of published articles was chosen to define the most prestigious and important contributions (top 100). Articles with high numbers of citations are likely those that impressed other clinicians/scientists and had profound influence on clinical practice or future developments in the field. Other definitions might have been possible but none of these is free from disadvantages and subjective judgment. It should be noticed that searches in different databases or with different key words will result in more or less variable citation counts and that the present results therefore provide only a snapshot. Self citation is likely to influence the final citation count of sparsely cited articles, whereas its impact on highly cited articles might be less pronounced. It was recently estimated that $6.4 \%$ of all citations per article (interquartile range 2.8-11.3, mean 8.4) were self citations [25]. Studies most vulnerable to this effect were those with more authors and small sample size.

Our results are consistent with previous analyses demonstrating that citation rate is gradually increasing for several years after publication [26,27]. However, the purpose of this overview was not to explore dynamics of citation count. Given the fact that most scientific oncology journals had steady increases in the number of published issues and articles, and that each article contains a certain number of references, the increase over time in total number of publications is expected to lead to a parallel increase in citation rates. It is also interesting to note that highly cited research (top 100) was published in a large number of different scientific journals ( $\mathrm{n}=21$ and 20 during the two time periods, respectively) with or without high impact factor, but always in the English language. In a previous study of radio surgery for various conditions, $1.5 \%$ of all articles (time period 19512010) achieved more than 100 citations [28]. These 85 articles were published in 19 separate journals. In a previous analysis restricted to German radiation oncology publications, most citations per year since publication were recorded for meta-analyses and randomized phase III trials [26]. The lowest figures were recorded for review articles, nonphase III prospective clinical trials, and retrospective clinical studies.

One of the most relevant findings from the present analysis, which clearly revealed changing pattern, is that the number of authors per highly cited article has increased significantly (>10 authors in 58\% vs. $25 \%$ of studies). This trend could be explained by the increasing complexity and multi-disciplinarily of radiation oncology and oncology in general. A previous study of authorship distribution limited to 4 
journals (Int J Radiat Oncol Biol Phys, J Clin Oncol, N Engl J Med, and Radiology) showed that radiation oncology publications (1975-2011) had a mean of 5.7 authors per publication [29]. Those published in the Journal of Clinical Oncology had significantly more authors (mean 8.9). Time trends were not explored.

Significantly fewer current top 100 articles (2009-2011) were published by authors from the US and/or Canada (53\% versus $73 \%$ ), while pure European contributions increased from $20 \%$ to $33 \%$. The proportion of publications related to breast, lung or lower gastrointestinal tract cancer increased, while that related to prostate or gynecological cancer decreased significantly. This should not be interpreted as general decrease in research activity related to these cancers. It is not uncommon that publication of landmark trials follows somewhat irregular time pattern where high activity might be followed by fewer completed studies. During both time periods, the majority of articles (59 and 60\%, respectively) reported on non-phase III clinical trials, and very few on radiobiology or physics research. Irrespective of time period, pattern of publication was dominated by only two scientific journals: the Journal of Clinical Oncology and the International Journal of Radiation Oncology Biology and Physics. However, the Journal of Clinical Oncology has strengthened its leading role (60\% versus $47 \%)$. Several newly launched journals (first issue after 1999) have managed to attract highly cited articles but the overall pattern of publication remains dominated by well established journals. Given that some of the newer journals, e.g. Lancet Oncology, Nature Reviews Clinical Oncology, or Nature Reviews Cancer, had rapidly increasing impact factors (currently approximately 12-35), one might speculate that pattern of publication could continue to evolve in the years to come. Apparently, despite controversy around impact factors and optimal evaluation of research productivity and quality [30,31], researchers still find it attractive and desirable to publish their most important radiation oncology related work in the top journals of the field.

\section{Conclusions}

Highly cited research was published in a large number of different scientific journals with or without high impact factor. However, the majority of articles appeared in relatively few well established journals. Important changes in pattern of publication, for example a considerable increase (more than double) in the proportion of articles written by more than 10 authors, were found.

The remaining articles (2009-2011) were published in 15 different journals (1 each). For the time period 1999-2001, the remaining articles were published in 13 different journals (1 each). Only one journal (Gynecol Oncol) featured remaining articles from both time periods. Several newly founded journals featured current top 100 articles, e.g. Radiat Oncol, JNCCN, Lancet Oncol, Nat Rev Cancer and Nat Rev Clin Oncol.

\section{References}

1. Rose PG, Bundy BN, Watkins EB, Thigpen JT, Deppe G, et al. (1999) Concurrent cisplatin-based radiotherapy and chemotherapy for locally advanced cervical cancer. N N Engl J Med 340: 1144-1153.

2. Keys HM, Bundy BN, Stehman FB, Muderspach LI, Chafe WE, et al. (1999) Cisplatin, radiation, and adjuvant hysterectomy compared with radiation and adjuvant hysterectomy for bulky stage IB cervical carcinoma. N Engl J Med. 340: 1154-1161.

3. Peters WA 3rd, Liu PY, Barrett RJ 2nd, Stock RJ, Monk BJ, et al. (2000) Concurrent chemotherapy and pelvic radiation therapy compared with pelvic radiation therapy alone as adjuvant therapy after radical surgery in high-risk early-stage cancer of the cervix. J Clin Oncol.18: 1606-1613.
4. Fu KK, Pajak TF, Trotti A, Jones CU, Spencer SA et al. (2000) A Radiation Therapy Oncology Group (RTOG) phase III randomized study to compare hyperfractionation and two variants of accelerated fractionation to standard fractionation radiotherapy for head and neck squamous cell carcinomas: first report of RTOG 9003. Int J Radiat Oncol Biol Phys. 48: 7-16.

5. Whitney CW, Sause W, Bundy BN, Malfetano JH, Hannigan EV, et al. (1999) Randomized comparison of fluorouracil plus cisplatin versus hydroxyurea as an adjunct to radiation therapy in stage IIB-IVA carcinoma of the cervix with negative para-aortic lymph nodes: a Gynecologic Oncology Group and Southwest Oncology Group study. J Clin Oncol.17: 1339-1348.

6. Urba SG, Orringer MB, Turrisi A, lannettoni M, Forastiere A, et al. (2001) Randomized trial of preoperative chemoradiation versus surgery alone in patients with locoregional esophageal carcinoma. J Clin Oncol 19: 305-313.

7. Creutzberg CL, van Putten WL, Koper PC, Lybeert ML, Jobsen JJ, et al. (2000) Surgery and postoperative radiotherapy versus surgery alone for patients with stage-1 endometrial carcinoma: multicentre randomised trial. PORTEC Study Group. Post Operative Radiation Therapy in Endometrial Carcinoma. Lancet 355: 1404-1411.

8. Paris F, Fuks Z, Kang A, Capodieci P, Juan G, et al. (2001) Endothelia apoptosis as the primary lesion initiating intestinal radiation damage in mice. Science 293: 293-297.

9. Brown JM, Wouters BG (1999) Apoptosis, p53, and tumor cell sensitivity to anticancer agents. Cancer Res 59: 1391-1399.

10. Pilepich MV, Winter K, John MJ, Mesic JB, Sause W, et al. (2001) Phase III radiation therapy oncology group (RTOG) trial 86-10 of androgen deprivation adjuvant to definitive radiotherapy in locally advanced carcinoma of the prostate. Int J Radiat Oncol Biol Phys. 50: 1243-1252.

11. Smith BD, Arthur DW, Buchholz TA, Haffty BG, Hahn CA, et al. (2009) Accelerated partial breast irradiation consensus statement from the American Society for Radiation Oncology (ASTRO). Int J Radiat Oncol Biol Phys 74: 987 1001.

12. Wiegel T, Bottke D, Steiner U, Siegmann A, Golz R, et al. (2009) Phase II postoperative adjuvant radiotherapy after radical prostatectomy compared with radical prostatectomy alone in pT3 prostate cancer with postoperative undetectable prostate-specific antigen: ARO 96-02/AUO AP 09/95. J Clin Oncol. 27: 2924-2930.

13. Wick W, Hartmann C, Engel C, Stoffels M, Felsberg J, et al. (2009) NOA 04 randomized phase III trial of sequential radiochemotherapy of anaplastic glioma with procarbazine, lomustine, and vincristine or temozolomide. J Clin Oncol 27: 5874-5880.

14. Fakiris AJ, McGarry RC, Yiannoutsos CT, Papiez L, Williams M, et al. (2009) Stereotactic body radiation therapy for early-stage non-small-cell lung carcinoma: four-year results of a prospective phase II study. Int J Radiat Oncol Biol Phys. 75: 677-682.

15. Willett CG, Duda DG, di Tomaso E, Boucher Y, Ancukiewicz M, et al. (2009) Efficacy, safety, and biomarkers of neoadjuvant bevacizumab, radiation therapy, and fluorouracil in rectal cancer: a multidisciplinary phase II study. J Clin Oncol 27: 3020-3026.

16. Stahl M, Walz MK, Stuschke M, Lehmann N, Meyer HJ, et al. (2009) Phase III comparison of preoperative chemotherapy compared with chemoradiotherapy in patients with locally advanced adenocarcinoma of the esophagogastric junction. J Clin Oncol 27: 851-856.

17. Gérard JP, Azria D, Gourgou-Bourgade S, Martel-Laffay I, Hennequin C, et al (2010) Comparison of two neoadjuvant chemoradiotherapy regimens for locally advanced rectal cancer: results of the phase III trial ACCORD 12/0405-Prodige 2. J Clin Oncol 28: 1638-1644.

18. Vaidya JS, Joseph DJ, Tobias JS, Bulsara M, Wenz F, et al. (2010) Targeted intraoperative radiotherapy versus whole breast radiotherapy for breast cance (TARGIT-A trial): an international, prospective, randomised, non-inferiority phase 3 trial. Lancet 376: 91-102

19. Aupérin A, Le Péchoux C, Rolland E, Curran WJ, Furuse K, et al. (2010) Meta-analysis of concomitant versus sequential radiochemotherapy in locally advanced non-small-cell lung cancer. J Clin Oncol 28: 2181-2190.

20. Carlson RW, Allred DC, Anderson BO, Burstein HJ, Carter WB, et al. (2009) Breast cancer. Clinical practice guidelines in oncology. J Nat Compr Canc Netw 7: 122-192.

21. Niyazi M, Maihoefer C, Krause M, Rödel C, Budach W, et al. (2011) Radiotherapy and "new" drugs-new side effects? Radiat Oncol. 6: 177. 
Citation: Nieder C, Geinitz H, Andratschke NH, Grosu AL (2013) Landmark Studies in Radiation Oncology: Has the Pattern of Publication Changed? J Cancer Sci Ther 5: 115-118. doi:10.4172/1948-5956.1000195

22. Estall V, Fairfoul J, Jena R, Jefferies SJ, Burton KE (2010) Skull base meningioma - comparison of intensity-modulated radiotherapy planning techniques using the moduleaf micro-multileaf collimator and helical tomotherapy. Clin Oncol (R Coll Radiol) 22: 179-184

23. Johnston ML, Vial P, Wiltshire KL, Bell LJ, Blome S, et al. (2011) Daily online bony correction is required for prostate patients without fiducial markers or softtissue imaging. Clin Oncol (R Coll Radiol) 23: 454-459.

24. Moghaddasi L, Bezak E, Marcu LG (2012) Current challenges in clinical targe volume definition: tumour margins and microscopic extensions. Acta Oncol 51: 984-995.

25. Kulkarni AV, Aziz B, Shams I, Busse JW (2011) Author self-citation in the general medicine literature. PLoS One 6: e20885.

26. Nieder C (2012) Highly cited German research contributions to the fields of radiation oncology, biology, and physics: focus on collaboration and diversity. Strahlenther Onkol 188: 865-872.
27. Stringer MJ, Sales-Pardo M, Nunes Amaral LA (2010) Statistical validation of a global model for the distribution of the ultimate number of citations accrued by papers published in a scientific journal. J Am Soc Inf Sci Technol 61: 13771385.

28. Kondziolka D (2011) Citation measures in stereotactic radiosurgery: publication across a discipline. Stereotact Funct Neurosurg 89: 56-61.

29. Holliday E, Fuller CD, Wilson LD, Thomas CR jr (2012) Success breeds success: authorship distribution in the Red Journal, 1975-2011. Int J Radiat Oncol Biol Phys 85: 23-28.

30. Kanaan Z, Galandiuk S, Abby M, Shannon KV, Dajani D, et al. (2011) The value of lesser-impact-factor surgical journals as a source of negative and inconclusive outcomes reporting. Ann Surg 253: 619-623.

31. Durieux V, Gevenois PA (2010) Bibliometric indicators: quality measurements of scientific publication. Radiology 255: 342-351. 